\title{
Cultura pop e performance: jogos identitários nos eventos de animê ${ }^{1}$
}

\section{Pop culture and performance: identity games at anime conventions}

Cíntia Sanmartin Fernandes ${ }^{2}$

Paula Rozenberg Travancas ${ }^{3}$

Resumo: A grande popularidade da cultura pop japonesa no Brasil, impulsionada pelo chamado boom dos animês nos anos 1990, levou à criação dos eventos de animê. Essas convenções, inicialmente voltadas para fãs de animações e seriados japoneses, hoje atraem neotribos (ou tribos urbanas) que se fundam no gosto por diversos segmentos da cultura pop mundial. Filiado à sociologia do cotidiano e do imaginário e apoiado em pesquisa de campo de inspiração etnográfica, este artigo parte da compreensão da estética como ética para vislumbrar o elã que permite a comunhão entre neotribos. Para tanto, são analisadas quatro atividades comuns aos eventos e que dependem da participação dos visitantes para ganharem vida: o cosplay, o animekê, os covers de k-pop e os videogames de dança. Tais atividades evidenciam modos de socialidade que produzem sentidos por meio da performance em suas dimensões de encenação, brincadeira e jogo.

Palavras-chave: eventos de animê; cultura pop; performance.

\footnotetext{
Abstract: The great popularity of Japanese pop culture in Brazil, driven by the so-called anime boom in the 1990s, led to the creation of anime conventions. These conventions, initially aimed at fans of Japanese animations and TV shows,

1 Uma primeira versão deste artigo foi apresentada ao grupo de trabalho Estudos de Som e Música no XXVI Encontro Anual da Compós - Faculdade Cásper Líbero, São Paulo, 6 a 9 de junho de 2017.

2 Universidade do Estado do Rio de Janeiro. Rio de Janeiro, RJ, Brasil. E-mail: cintiasan90@ gmail.com

3 Universidade do Estado do Rio de Janeiro. Rio de Janeiro, RJ, Brasil. E-mail: ptravancas@gmail. com
} 
now gather neotribes, or urban tribes, that are grounded in the taste for various segments of global pop culture. Subscribing to the sociology of everyday life and of the imaginary, and supported by field research of ethnographic inspiration, this paper is rooted in the understanding of aesthetics as ethics to glimpse the elan that allows the communion between neotribes. To do so, five activities common to conventions that depend on the participation of visitors to come to life are analyzed: cosplay, animeke, $k$-pop covers and dance video games. These activities demonstrate modes of sociality that produce meanings through performance, in its dimensions of acting, play and game.

Keywords: anime conventions; pop culture; performance. 
Foi-se o tempo em que qualquer menção a animês ou mangás em textos acadêmicos ou na mídia tradicional precisava ser prefaciada por longas explicações sobre o que são as animações e histórias em quadrinhos japonesas. O Japão, ou ao menos esse aspecto de sua indústria de entretenimento, não só é pop, ${ }^{4}$ como mainstream. Nesse sentido, partimos do pressuposto de que a ideia de cultura pop diz respeito tanto aos produtos em si quanto aos sentidos engendrados e circulados por eles, que passam a integrar, ainda que efemeramente, o repertório de imaginários das pessoas que os consomem. Por mais que os produtos da cultura pop inevitavelmente tenham marcas de seu tempo e de seu(s) lugar(es) de origem, eles também têm um certo ar de desenraizamento cosmopolita que, ao mesmo tempo, remete pessoas de diferentes lugares a uma territorialidade comum. A cultura pop, desse modo, "estabelece formas de fruição e consumo que permeiam um certo senso de comunidade ou compartilhamento de afetos e afinidades que situam indivíduos dentro de um sentido transnacional e globalizante" (SOARES, 2015, p. 22).

Assistir aos animês e ler mangás fica mais fácil a cada dia, tanto para fãs dedicados quanto para públicos mais casuais. Muito mudou desde os "longínquos" anos 1990, década em que os animês se tornaram febre nacional. Os otakus da época, termo pelo qual são conhecidos hoje os fãs da cultura pop japonesa, tinham de se desdobrar para assistir a mais do que as poucas produções nipônicas exibidas na televisão brasileira. Ávidos por mais animês e tokusatsu, ${ }^{5}$ precisavam recorrer a fitas VHS, muitas vezes sem legenda, obtidas em um número seleto de locadoras especializadas ou copiadas de amigos (MACHADO, 2009).

Dada a dificuldade para ter acesso aos animês, os otakus da década de 1990 se organizavam em clubes e promoviam exibições de animê, que também serviam para conhecer outros fãs da cultura pop japonesa. Tais

4 A cultura pop se refere ao que, no Brasil, é chamado de popular massivo ou popular midiático, ou seja, uma gama de artefatos culturais produzidos sob a lógica das indústrias do entretenimento que tem como objetivo o consumo em massa, seja pelo "grande público" ou por algum nicho específico (SOARES, 2015).

5 Filmes ou séries de efeitos especiais com atores reais, normalmente sobre super-heróis, monstros e robôs. Alguns dos tokusatsu de sucesso no Brasil foram National Kid, Jaspion, Changeman e Ultraman. 
exibições deram origem aos eventos de animê, encontros que foram, aos poucos, deixando para trás as sessões de desenhos animados e tokusatsu, mas passaram a oferecer diversas outras atrações.

Seguindo a fórmula que se consagrou, os eventos de animê acontecem aos fins de semana, podendo durar os dois dias ou só o domingo, em espaços alugados como universidades, clubes ou centros de convenções. Costuma haver pelo menos um palco, onde se desenrolam as atrações com hora marcada, como concursos de cosplay, ${ }^{6}$ palestras de dubladores ou youtubers e shows de música. O resto do espaço se divide em áreas que abrigam atividades diversas que costumam ficar disponíveis durante o evento todo, tais como jogos de videogame, RPGs e trading card games, combate medieval ${ }^{7}$ e animekê. ${ }^{8}$

De encontros de algumas centenas de pessoas, esses eventos cresceram e se multiplicaram, passando a ocorrer com regularidade em todo o país. A história da relação dos brasileiros com a cultura pop japonesa e dos eventos de animê que daí surgiram e se modificaram contribuiu para os rumos da investigação, que adotou, ao longo dos últimos dois anos, como estratégia metodológica a pesquisa de campo de inspiração etnográfica, consistindo em observação participante em seis eventos no Rio de Janeiro e um em São Paulo. A variedade de neotribos urbanas, ${ }^{9}$ com suas respectivas estéticas evidenciadas pela pesquisa, levou à análise de atividades participativas frequentemente oferecidas nos eventos, na tentativa de dar a ver o que há de comum entre essas práticas, nos aproximando, assim, do elã que potencializa a comunhão de imaginários e identificações dos diversos grupos ali presentes.

É importante ressaltar ainda que, conforme Campos (2010, p. 4),

6 Fantasia de personagem de animê, mangá, videogame ou de qualquer tipo de mídia de entretenimento.

7 Simulação de luta com armas de espuma.

8 Caraoquê com músicas de animê.

9 Maffesoli, em seu livro O tempo das tribos, sugere ver os grupos sociais na sociedade atual como espécies de "neotribos", como comunidades fundadas na "emoção": "[...] a comunidade emocional é instável, aberta, o que pode tornála, sob muitos aspectos, anômica com relação à moral estabelecida" (MAFFESOLI, 1987, p. 22). Essas "novas tribos" da sociedade contemporânea, "[...] ao contrário da estabilidade do tribalismo clássico [...], se caracterizaria[m] pela fluidez, pelos ajuntamentos pontuais e pela dispersão" (MAFFESOLI, 1987, p. 107). 
[...] o esgotamento do pensamento de inspiração marxista da escola de Birmingham e, simultaneamente, a emergência de contextos socioculturais juvenis renovados levam muitos investigadores a adotarem quadros conceptuais regenerados, organizados em torno de conceitos como "estilo de vida", "cena" ou "neotribo" (BENNETT e KAHN-HARRIS, 2004), abarcando aquilo que, de forma algo genérica, é entendido como "estudos pós-subculturais" (WEINZIERL e MUGGLETON, 2004).

Desse modo,

[...] o conceito de tribo, ou neotribo, tomado de empréstimo a Michel Maffesoli (1987), surge, igualmente, neste movimento de reavaliação de paradigmas, com uma moldura analítica mais consentânea com os novos contextos empíricos onde se localizam os jovens. Enquanto as subculturas eram percebidas como um todo internamente coerente, relativamente rígido e uniforme, com uma sustentação ideológica que remetia para o conflito de classes, as tribos parecem existir mais pelo efêmero, contraditório, pela ligação emocional aparentemente despolitizada, pela metamorfose e fusão gregária de contornos híbridos. A noção de tribo juvenil não ignora, também, o vigor da imagem e da representação visual, na medida em que vincula os indivíduos a uma linhagem que não resulta de determinantes estruturais, mas mais de opções estético-estilísticas, emocionais e gregárias, que se denunciam em grande medida no domínio do performativo e da aparência. Aliás, o termo "tribo" não pode deixar de evocar um imaginário repleto de exotismo, que reconhece na superfície dos corpos indícios de diferença e distância (CAMPOS, 2010, p. 5).

\section{Performances e jogos identitários}

Nem toda performance é socialmente demarcada por "papéis sociais" predeterminados (GOFFMAN, 1983). Qualquer interação cotidiana requer que os participantes atuem a partir do jogo social em ato. Nessa teatralidade do cotidiano - em que acionamos diversos "eus" nas interações com os outros -, vivemos processos de identificação e de diferenciação, constantemente compondo e recompondo o que entendemos como nossa própria individualidade. 
Esse vir a ser que ocorre no contato com o outro é sempre precário, cambiante e transitório, uma vez que não falamos de uma identidade e sim de uma persona, uma das muitas máscaras que vestimos em nossas interações sociais. A máscara não representa algo falso, mas um papel desempenhado de acordo com o contexto e que exprime uma parcela da verdade daquilo que somos. Como sintetiza Maffesoli (1987, p. 15), “a pessoa (persona) só existe na relação com o outro". Portanto, "ser" otaku, gamer, cosplayer ou qualquer outro tipo de pertencimento tribal é sempre um modo de ser circunscrito não só às mudanças de gosto dos indivíduos, mas também aos momentos e pessoas com quem é possível "ser" certa coisa e não outra ou mais de uma coisa ao mesmo tempo.

A multiplicidade de imaginários acionados pelas diferentes atividades dos eventos se corporifica nas diversas estéticas que lá encontramos. Os cosplays, as roupas, os adereços e os modos próprios de comunicação fazem parte dos pertencimentos tribais que podem ser identificados nos eventos. As vestimentas e a apresentação de si são de central relevância na fruição dos eventos, que se tornam espaços em que as pessoas podem usar roupas e acessórios ou adotar comportamentos que seriam malvistos fora dessas ocasiões. O acordo tácito é que cada um tem a liberdade de ser como é (ou gostaria de ser) sem temer ser julgado pelo modo como se faz perceber.

As roupas e acessórios funcionam tanto como marcadores de pertença quanto de diferença, o que permite que os significados de cada peça ou estampa sejam lidos pelos outros participantes do evento, uma vez que a maioria dos presentes domina aqueles códigos. Uma das funções das roupas nos eventos, assim, é de serem chamarizes à interação, já que um dos grandes atrativos dos eventos é estar na presença de outros apaixonados pela cultura pop. Desse modo, a roupa potencializa a estética comunicativa do grupo.

Para muitos frequentadores de eventos, os cosplays ou as peças de roupas e adereços que vestem nessas ocasiões representam mais a realidade de quem eles são do que as roupas que vestem na vida cotidiana, de modo que é 
[...] como se, ao disfarçar-se de personagens de desenhos animados, os jovens chegassem a encontrar sua verdadeira personalidade. Como se a roupa insípida de todos os dias fosse de fato o verdadeiro disfarce (BARRAL, 2000, p. 140).

Muitos frequentadores vestem camisetas pretas de bandas, de animê ou de games, mas, mesmo quando não estão vestidos de algum personagem ou segundo algum estilo específico, usam muitos adereços e acessórios que marcam seu pertencimento à tribo. Usam colares metálicos com pingentes (para moças e rapazes), sobretudos, luvas, presilhas de cabelo, chaveiros e bótons na bolsa ou mochila, os quais podem ou não fazer menção a personagens ou séries específicas. Há também as touquinhas, orelhinhas e rabos de bichinho, que são usados por garotos e garotas.

Todos esses elementos tornam difícil identificar até onde vai a simples composição de acessórios e onde começa o cosplay. Esses modos de vestir as paixões trazem à tona a importância do corpo na socialidade, o qual serve como um outdoor afetivo que convida o contato de outros membros da tribo. É comum, nos eventos de animê, uma pessoa iniciar uma conversa com outra apenas por tê-la visto usando uma camiseta ou bóton de um animê ou série do qual também gosta.

Entre otakus, gamers, cosplayers, nerds, geeks e muitos outros grupos, essas convenções podem ser caracterizadas como "eventos intertribais" (MACHADO, 2009, p. 117). O sentimento de pertença a uma ou mais neotribos é fluido, dinâmico e ambivalente, não havendo fronteiras claras nem exclusividade entre os diversos grupos (MAFFESOLI, 1987). Assim, os espaços dos eventos de animê são marcadamente heterotópicos, já que "têm o poder de justapor em um só lugar real vários espaços, vários posicionamentos que são em si próprios incompatíveis” (FOUCAULT, 1984, p. 411).

As diferentes atrações e atividades que convivem no mesmo evento estão em constante negociação de espaço físico e simbólico. Essa tensão de heterogeneidades, longe de abalar o convívio das neotribos, promove a diversidade que solidifica o conjunto (MAFFESOLI, 1987). As várias 


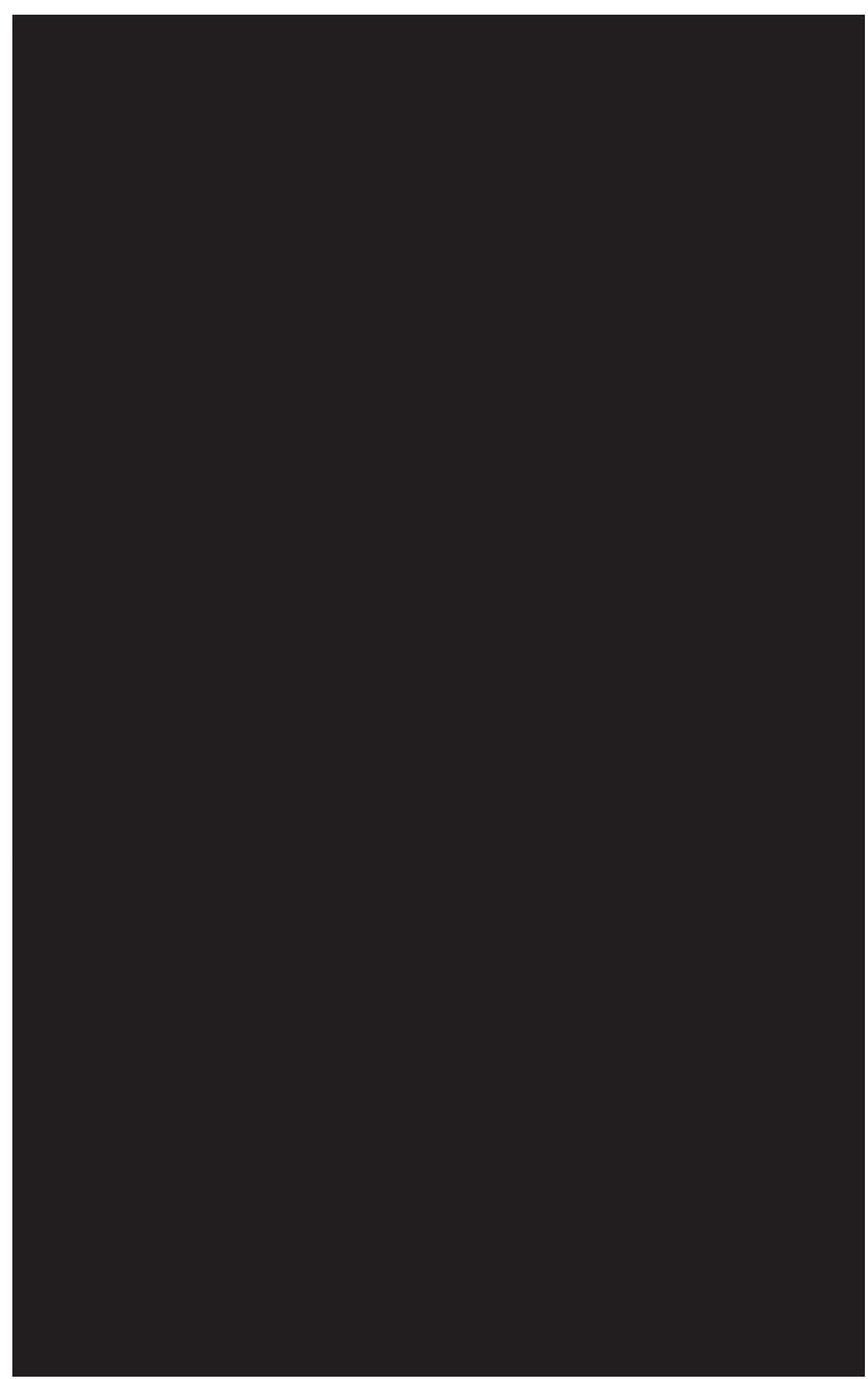


vezes vivenciados", ações realizadas para as quais as pessoas treinam ou ensaiam (SCHECHNER, 2006, p. 28, tradução nossa). ${ }^{10}$

As práticas analisadas ao longo de nossa pesquisa carregam certo grau de autorreflexividade (GIDDENS, 2002) dos participantes, uma vez que se admitem implicitamente como comportamentos restaurados. Evocam e corporificam algum "outro", algum "não eu” ao qual a performance faz referência, uma atividade que se assume outra no tempo ou no espaço.

Assim, o que delimitamos aqui como performance é o "ato de presença no mundo e em si mesma” (ZUMTHOR, 2007, p. 67). A partir de Zumthor (2007) - que recupera as concepções de Merleau-Ponty -, compreendemos que podemos encontrar no corpo discursos tão potentes quanto os apreendidos nos textos e na oralidade. Nas inscrições corpóreas, podemos desvelar os sentidos dos textos culturais. Desse modo, argumenta o autor:

Meu corpo é a materialização daquilo que me é próprio, realidade vivida e que determina minha relação com o mundo. Dotado de uma significação incomparável, ele existe à imagem de meu ser: é ele que eu vivo, possuo e sou, para o melhor e para o pior (ZUMTHOR, 2007, p. 23).

A experiência dos cosplays, animekês e covers de k-pop é mais do que simplesmente se vestir a caráter, envolvendo também a interpretação (ou performance), materializada na postura, no jogo das identificações, na compreensão do que é ser os diversos personagens. Na prática dessas performances, os indivíduos modificam o conhecimento, atualizam virtualidades e concretizam imaginários.

\section{Cosplay}

O cosplay, atividade de maior prestígio dentro dos eventos (MACHADO, 2009), é também aquela à qual foi dispensada mais atenção acadêmica. Trata-se do ato de se vestir como personagens de narrativas midiáticas, 'restored behaviors', 'twice-behaved behaviors', performed actions that people train for and rehearse". 
sejam elas animês, livros, filmes, jogos, seriados ou até celebridades "de carne e osso".

Cosplay é a junção das palavras costume, fantasia, e play, termo de difícil tradução que passeia entre os sentidos de "brincadeira", "jogo” e "peça teatral” (DAWSEY, 2007). A prática de criar e vestir fantasias de personagens midiáticos em convenções se originou nos Estados Unidos em 1939, com personagens da ficção científica. O primeiro registro desse tipo de atividade no Japão é de 1978. O termo cosplay foi cunhado em 1983 nesse mesmo país, onde a prática se popularizou enormemente (SOARES, 2013). A chegada do cosplay ao Brasil data de 1996, quando foi realizado o evento Mangácon.

Praticamente todos os eventos de animê atuais contam com competição de cosplay. É muito comum ver pessoas circulando fantasiadas pelos eventos, algumas das quais preferem não se apresentar no palco. Aparecer de cosplay praticamente garante a qualquer um o status instantâneo de semicelebridade, nem que seja só até o final da convenção ou até a pessoa se "desmontar".

Há o acordo implícito de que, ao aparecer fantasiado, o cosplayer está disposto a posar para as fotos que os demais frequentadores pedirão para tirar. Nesses momentos, é comum o cosplayer fazer alguma pose característica do personagem que está encarnando. Ao andar pelo evento, o cosplayer é um "não eu” e um "não não eu” (SCHECHNER, 2011), podendo, a qualquer momento, precisar ou querer performatizar o personagem. Enquanto vestir a fantasia, é "como se" ele fosse o personagem, vivendo na ambiguidade de uma dupla identidade.

O concurso de cosplay geralmente ocorre no palco principal. Costuma se subdividir nas seguintes categorias: a) desfile, em que apenas a fantasia e a caracterização são avaliadas; b) tradicional, em que um ou mais cosplayers interpretam alguma cena canônica do animê (ou outra mídia) de origem dos personagens; c) livre, em que os cosplayers criam uma cena original com aqueles personagens, normalmente em situações de humor (SOARES, 2013). 
Figura 1 - Cosplayers que não estavam originalmente juntos, mas que, fantasiados de personagens da editora de quadrinhos DC, se reúnem espontaneamente para posar para a foto.

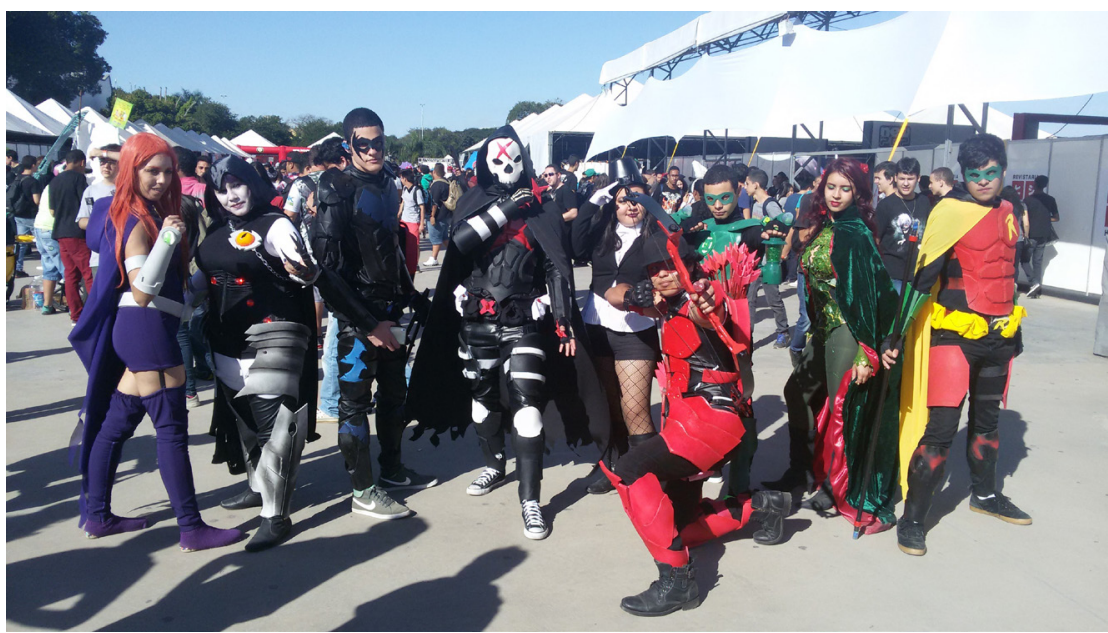

Assim, cosplay não significa apenas vestir a fantasia, mas também interpretar um personagem. Também não é apenas imitar, já que são criadas cenas novas, seja no palco ou fora dele, visto que os cosplayers posam para fotos nas quais criam situações que nunca ocorreram no material original. Os cosplays permitem que inimigos se beijem e que personagens de diferentes franquias posem para fotos como se estivessem lutando entre si. O próprio cosplay pode ser uma adaptação ou recriação do personagem e independe da diferença entre o gênero e características físicas do cosplayer e do cosplay. Há versões femininas de personagens masculinos (e vice-versa), situações nas quais o cosplayer não só se veste de um personagem cujo gênero é diferente do seu, mas adapta a roupa toda, de modo que é como se aquele personagem realmente fosse de outro gênero.

A escolha do personagem pelo cosplayer costuma se dar por afinidades físicas ou psicológicas, pelo desafio de elaborar uma boa fantasia ou ainda para participar de uma performance em grupo com amigos. 
Figuras 2 e 3 - Rapaz vestido de Mileena, do game Mortal Kombat, e versão feminina do Coringa ao lado de cosplay da versão tradicional do personagem no Anime Friends 2015.

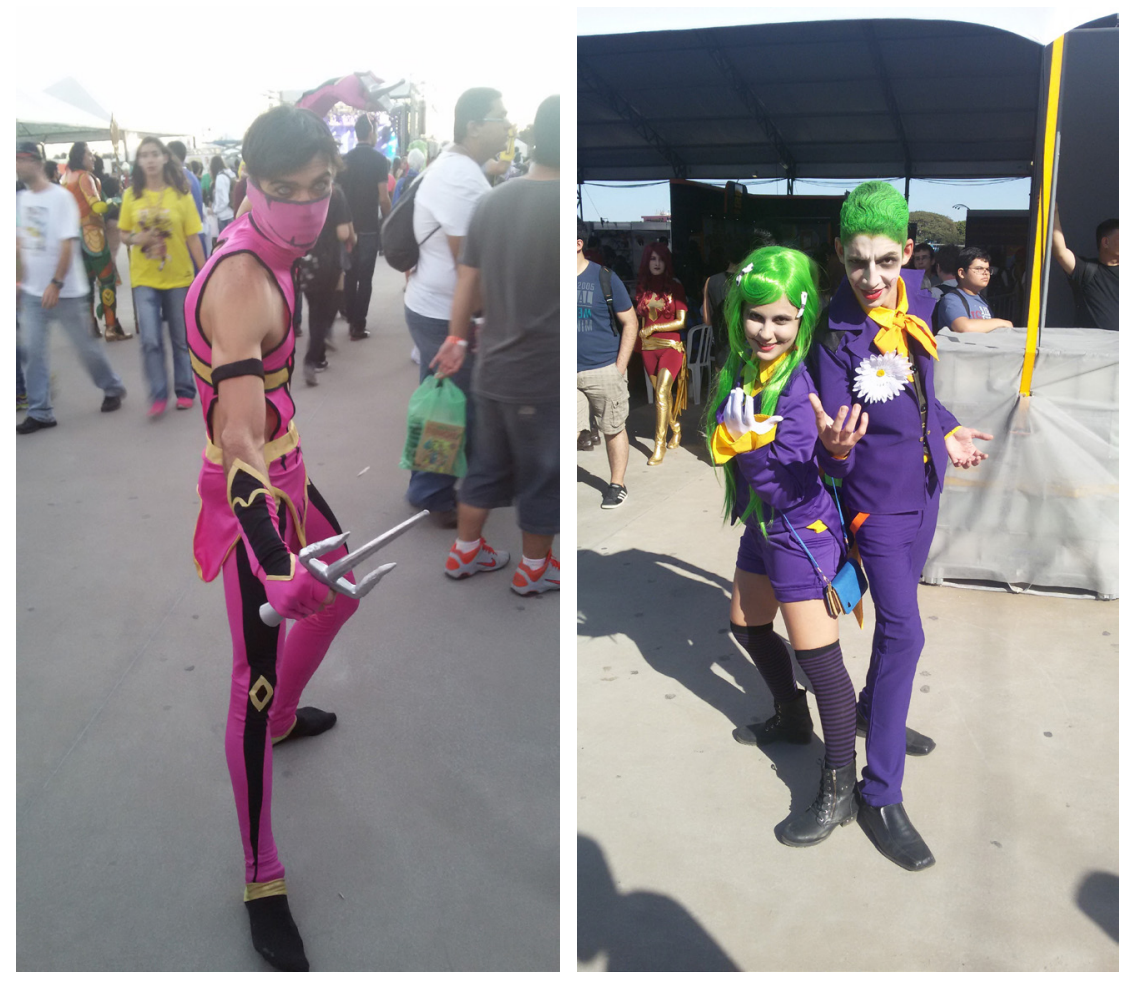

Segundo Nunes (2015, p. 45), “o cosplay, compreendido como metonímia das narrativas hegemônicas, mangás, animês, entre outras, reinventa a narrativa original no corpo dos jovens por meio das materialidades consumidas". É desse modo, por meio da escolha afetiva e do caráter transformador da performance (SCHECHNER, 2011), que o cosplayer, ao mesmo tempo, incorpora o personagem e realiza processos de negociação identitária, acionando para si próprio algo daquele personagem ou daquela performance.

\section{Animekê}

Da centralidade das roupas e do gesto, passamos à centralidade da voz, importante elemento da performance em sua materialidade (ZUMTHOR, 
2007). A questão da fala se manifesta também no cosplayer, que fala com sua própria voz ou pode ser "dublado" por meio de lip sync, mas o animekê traz o performer ao registro do canto. Animekê, junção de animê com caraoquê, é igual ao último: a pessoa canta com o acompanhamento instrumental gravado da própria música. O que distingue o animekê é a seleção de músicas, que podem ser anime songs, ${ }^{11}$ músicas de videogame, de tokusatsu ou ainda j-music ${ }^{12}$ (MACHADO, 2009).

Karaoke é a junção de kara (vazio) e oke (abreviando okesutora, fonetização japonesa de "orquestra"), significando algo como "sem orquestra”. A atividade surgiu no Japão nos anos 1970 e, nos anos 1980, se popularizou no país e se espalhou pelo mundo, sendo até hoje uma forma de diversão amplamente praticada por lá.

Em seu país de origem, o caraoquê é uma atividade de socialização, regida pela modéstia e busca da harmonia do grupo, características notórias do viver social japonês. O importante ao se reunir com amigos ou colegas de trabalho para cantar é se esforçar, dar o melhor de si. Cantar desafinadamente nessas ocasiões não é motivo de vergonha, e sim uma atividade desestressante que promove a união por meio da diversão e da "vulnerabilidade" de todos os presentes.

Ao vir para o Ocidente, os caraoquês foram apropriados como uma atividade competitiva e de reafirmação individual, mesmo que essa competitividade faça parte da brincadeira nesse ritual social. Evidência disso são os viodeoquês caseiros que atribuem nota ao desempenho do cantor (SATO, 2007). Os eventos de animê juntam esses dois aspectos do caraoquê: ao mesmo tempo que é um ambiente seguro em que as pessoas podem se sentir livres para serem elas mesmas e cantar de qualquer jeito as músicas de que gostam, há aquelas que o fazem em nível competitivo.

O animekê pode acontecer em um palco ou espaço dedicado ou no palco principal. Há o animekê livre, em que a pessoa canta sem

11 Canções de trilhas sonoras de animês.

12 Música japonesa contemporânea, normalmente pop ou rock. 
compromisso, e os concursos, nos quais os participantes são julgados por seu desempenho e concorrem a prêmios.

Algumas pessoas escolhem músicas de animês que têm versão em português, mas é muito comum os participantes escolherem músicas em japonês, que não têm dificuldade em cantar, ainda que não dominem a língua. Esse fato impressiona muitos não otakus, mas é tratado com naturalidade nos eventos. Isso porque, ainda que não tenham feito curso de japonês, os fãs de animê estão acostumados com a sonoridade da língua.

Como a oferta de animês dublados no Brasil é relativamente pequena nos dias de hoje, os otakus recorrem à internet, onde facilmente encontram desenhos legendados (LOURENÇO, 2009). Essa legendagem costuma ser feita por fãs, que traduzem diretamente do japonês ou de outras legendas já existentes, atividade conhecida como fansub. É de tanto ouvir a língua japonesa em animês, filmes, novelas e músicas que os otakus acabam aprendendo a pronúncia, a cadência e até a impostação de voz japonesa.

Tanto cantar quanto aprender outro idioma, ainda que apenas a maneira de vocalizá-lo, desconhecendo-se seus significados, são técnicas corporais que fazem uso do aparelho fonador humano. São aprendidas, como quaisquer outras, por imitação e treino, atos que requerem a assimilação de movimentos (MAUSS, 1974); nesse caso, movimentos que produzem voz e melodia.

Outra atração comum nos eventos são as bandas de rock, normalmente fazendo covers de músicas de animês e videogames. Essa atração, no entanto, por ser um serviço contratado previamente pelos organizadores, não entra no escopo das atividades em que qualquer frequentador pode participar e competir. Os nomes das bandas, que normalmente têm algum grau de fama na mídia mainstream ou no YouTube, são anunciados como parte formal da programação.

\section{K-pop covers}

Pode parecer estranho que a música pop sul-coreana tenha conquistado um enorme espaço nos eventos de cultura pop japonesa nos últimos 
anos. Essa expansão, no entanto, fica clara uma vez que examinamos o fenômeno da Hallyu. Esse termo, que literalmente significa "fluxo coreano", mas é mais conhecido como "onda coreana", marca a rápida ascensão da Coreia do Sul como país exportador de produtos culturais para o mundo todo. Inicialmente propelida pela disseminação das novelas coreanas (conhecidas como k-dramas) no sudeste asiático, a Hallyu ganhou força mundial no começo dos anos 2000 por meio do $k$-pop.

Abreviação de Korean pop, o k-pop vai além do estilo musical de batida marcante que tem influência de gêneros norte-americanos como música eletrônica, RשB e hip-hop. O fenômeno engloba também a estética de seus coloridos videoclipes, em que os integrantes das bandas vestem roupas da moda e executam coreografias altamente sincronizadas. Essas boy e girl bands (raramente mistas) são resultado de verdadeiras fábricas de talento, recrutando crianças e adolescentes para a chance de um dia virarem idols. Esses jovens são treinados exaustivamente durante anos para virarem estrelas que agradem aos mercados globais (KARAM e MEDEIROS, 2015).

A internet foi fundamental para espalhar pelo mundo o gosto pelo $k$-pop. Os sites de redes sociais permitem a comunicação entre os ídolos coreanos, que aprendem outras línguas em seu treinamento, e suas bases de fãs internacionais, fortalecendo sua imagem e dando a sensação de serem pessoas acessíveis, "gente como a gente". Já o YouTube permitiu que os clipes e shows das bandas fossem facilmente compartilhados pelos fãs, que começaram a gravar seus próprios covers das coreografias de k-pop e disponibilizá-los na plataforma de vídeos (JUNG, 2011). A internet é essencial também para a comunicação e a formação de redes entre os fãs, que podem compartilhar seus gostos com pessoas de seu país e do mundo, aprender uns com os outros e organizar encontros off-line.

Daí nasceram os k-covers, prática em que os fãs de $k$-pop aprendem e executam, normalmente em grupo, as coreografias de seus clipes preferidos. Como os eventos de animê abrangem cada vez mais interesses e a própria Hallyu ganhou muita força por meio do mercado japonês, 
não demorou até que os covers de $k$-pop virassem parte da programação. Como especula Sasaki (2013), descendentes de japoneses talvez não se sentissem confortáveis com a inclusão da cultura pop sul-coreana na programação dos eventos de animê devido à história complicada entre os dois países. Esse aparente desencontro, no entanto, não é uma preocupação para a maior parte dos brasileiros, o que não significa dizer que não haja conflitos entre os otakus, antigo público-alvo principal dos eventos, e os mais recém-chegados fãs de $k$-pop.

Nos concursos dos eventos, não raro etapas de concursos maiores (assim como os das demais atividades aqui relatadas), há categorias em que só são permitidos covers da dança original e outras - livres - em que os participantes podem fazer mashups ${ }^{13}$ de músicas e criar suas próprias coreografias. Por vezes, há divisão entre as apresentações solo, em dupla e em grupo. Nos concursos menores, é comum só haver uma modalidade, que acaba recebendo poucos participantes solo, já que a sincronização de movimentos entre os dançarinos é de grande importância para tornar a performance impactante. As equipes buscam a coordenação nos gestos e também no visual caprichado, apostando em roupas iguais ou combinando, quase sempre com peças bastante coloridas.

Há desde coreografias mais simples, que podem ser praticadas por iniciantes, até as mais complexas, que requerem alto grau de treino e habilidade. Alguns grupos escolhem apresentações mais "fofas", elemento que o $k$-pop tem em comum com o j-pop (música pop japonesa), outros exibem mais sensualidade nas roupas e nos movimentos, fazendo jus à influência norte-americana da música sul-coreana. Alguns k-poppers (fãs de $k$-pop, quer dancem ou não) buscam se aproximar da aparência asiática, o que às vezes se revela difícil devido às diferenças de constituição física entre os corpos brasileiros e os de seus ídolos coreanos.

As técnicas corporais necessárias para a execução das coreografias do $k$-pop são aprendidas por meio de produtos para consumo massivo acessados pela internet. Os $k$-poppers imitam e reproduzem as coreografias a que assistem, mas também as ressignificam e com elas negociam, já que

13 Faixa que combina trechos de duas ou mais músicas. 
essas técnicas se sobrepõem a corpos que já contam com um repertório gestual e simbólico prévio assimilado durante anos em meio à cultura e aos modos de ser dos brasileiros.

\section{Videogames de dança}

Ainda no âmbito das coreografias, outra forma de diversão popular nos eventos são os videogames de dança. Esse gênero de game surgiu no Japão como evolução dos jogos de ritmo, em que o jogador usava o direcional do controle para acompanhar os comandos em forma de setas, acertando a batida da música. Lançado em 1998, Dance Dance Revolution (DDR) deu ao jogador o comando das setas por meio de botões sob seus pés, fazendo com que precisasse pisar nos lugares certos conforme as ordens que apareciam na tela.

Nos primeiros anos do século XXI, DDR virou moda nos eventos de animê, eles mesmos recém-estabelecidos no Brasil. Os jogos de dança evoluíram e mudaram, o que se refletiu em sua presença nos eventos. À moda do DDR se seguiu a do Pump It Up, muito parecido com o anterior, mas acrescentando setas na diagonal, não só cima, baixo, frente e trás. Depois houve o momento do jogo Para Para Paradise, que usava sensores no chão para detectar os braços do jogador, trazendo o foco da dança aos membros superiores.

O surgimento do console Nintendo Wii marcou uma nova era para os jogos de dança, aliando sensores de movimento ao giroscópio embutido no controle. Para o Wii foi lançado Just Dance, jogo de 2009 da multinacional francesa Ubisoft. Com gráficos coloridíssimos, jogabilidade mais intuitiva e uma seleção de hits famosos, o game alcançou enorme popularidade até entre pessoas que não tinham o costume de jogar videogames. Outra grande diferença desse novo tipo de jogo de dança é que, ao contrário do DDR e similares, em que a música era interrompida após muitos erros do jogador, causando frustração, a geração do Just Dance permite que o jogador continue a jogar até o fim da música, facilitando o processo de aprendizado das coreografias. 
Xbox, da Microsoft, elevou a jogabilidade dos games de dança. Ao usar esse sistema para jogar Just Dance 2016, versão mais atual da série, o jogador usa seu corpo inteiro para interagir com o console (SILVA, 2013). Não é mais preciso segurar controles, já que ele conta com uma câmera que capta os movimentos do jogador. Mais do que nunca, não basta mover os pés ou as mãos para "enganar" o jogo, é preciso participar de corpo inteiro.

Nos eventos de animê, o Just Dance e, às vezes, seu concorrente Dance Central são jogados em um espaço delimitado no "chão" do próprio evento. Apenas em convenções maiores ou em fases de torneios maiores existe um palco específico para esses jogos. Os games de dança costumam ser jogados nos eventos com o número máximo possível de participantes, dois no Dance Central e quatro no Just Dance.

Figura 4 - Just Dance no Rio Geek Zone 2015.

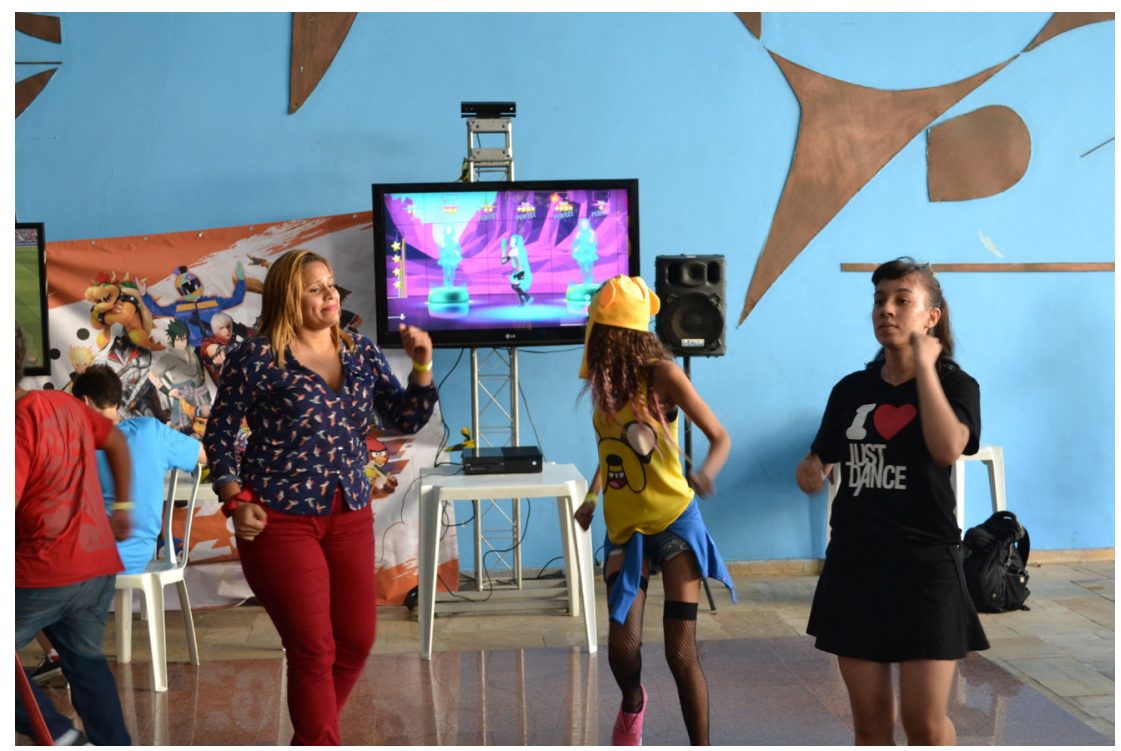

É interessante notar que, em volta dos jogadores, se forma uma roda de pessoas que também conhecem a coreografia e a executam como se 
estivessem participando, fenômeno também percebido na plateia que assiste às apresentações de $k$-covers.

Contudo, os dançarinos/jogadores de Just Dance e Dance Central precisam se preocupar menos com a própria imagem do que aqueles do $k$-pop. Assim, não precisam se vestir de certo modo para dançar nem se preocupar em manter uma forma física dentro dos padrões de beleza e magreza, já que quem decide o vencedor é o videogame, que não tem como considerar os aspectos subjetivos da performance.

Em contraste com as outras práticas que analisamos, os games de dança são os únicos feitos com o objetivo de serem imitados. O jogo só se completa quando os jogadores corporificam os movimentos dos bonecos que aparecem na tela, bonecos esses que já são releituras ou recriações das performances dos artistas em cuja música se baseia a coreografia. Diferentemente de outros jogos musicais, como Guitar Hero e DJ Hero, os jogos de dança fazem o jogador de fato dançar, não apenas simular o ato de tocar um instrumento.

Dançar pode fazer parte da experiência de fruição musical, mas os jogos de dança saem da esfera mais ampla da brincadeira e da representação para se formalizar em regras claras. Assim, entre as atividades disponíveis nos eventos, o jogo de dança é o que mais parece borrar as fronteiras entre performance e jogo, com notas "objetivas" e, ao mesmo tempo, uma presença sensível que se torna apresentação ante o olhar do outro.

Desse modo, o game de dança dificilmente pode ser divorciado de sua dimensão de jogo, ainda que não esteja sendo jogado de modo competitivo. As instruções da tela, no entanto, não são apenas seguidas, mas traduzidas, interpretadas e negociadas entre jogadores e jogo, entre dançarinos e plateia. O caráter competitivo dos jogos eletrônicos de dança se aproxima das outras performances do evento no engajamento da plateia, cujas reações também fazem parte do "texto performático" (SCHECHNER, 2011), podendo engajar seu corpo e sua voz na torcida por algum dos competidores. 


\section{Considerações finais}

Todas as atividades abertas à participação dos frequentadores materializam, no corpo desses sujeitos, o desejo de fazer contato com pessoas e estéticas outras, que, por vezes, remetem a modos de ser distantes dessas pessoas, tanto no espaço quanto no tempo. Os frequentadores dos eventos de animê atualizam e ressignificam conteúdos midiáticos e imaginários culturais. Tais imagens carregam, para esses fãs da cultura pop, grande "potência estético-comunicativa", ${ }^{14}$ interessando-os pela própria ambiguidade de serem "outros" deles mesmos e de terem com eles características em comum que permitem a criação de vínculos afetivos com essas imagens. Tornam-se para eles vetores de comunhão e signos de diferenciação individual/tribal em relação ao todo social.

Sejam os personagens midiáticos dos cosplays, as vozes das anime songs, os clipes sul-coreanos dos covers de k-pop, os avatares dos games de dança, os frequentadores dos eventos corporificam e materializam imaginários e textos midiáticos. Incorporam algo dessas imagens outras a si mesmos devido às experiências transformadoras da performance $\mathrm{e}$ da festa, que funcionam como lócus de negociação de identidades e de comunidade.

Por meio do movimento de corpos encarnados e semantizados, os fãs da cultura pop produzem sentidos e criam, nas espacialidades efêmeras dos eventos de animê, microterritórios relacionais que lugarizam os espaços e estetizam o cotidiano por meio de sua presença sensível, sua aparência, seus imaginários e modos de ser. Em sua relação de integralidade com os outros e com os espaços, vivem interações e produzem performances, comportamentos restaurados, porém únicos em seu contexto e execução, que reúnem aspectos da encenação, da brincadeira e do jogo.

14 Potência não apenas racionalizável, mas sensitiva, afetiva, emocional, possibilitada pela estética mundana. Estética que aproxima e comunica as diferentes comunidades dentro da globalidade, na qual a comunicação, seja por qual meio se dê, é a garantia do estar-junto mais primário, independente de contratos sociais e ações deliberativas. É uma agregação e união que está na base societal, compondo o húmus comunitário (FERNANDES, 2009). 


\section{Referências}

AMARAL, R. As mediações culturais da festa. Revista Mediações, v. 3, n. 1, p. 13-22, jan.-jun. 1998.

BARRAL, É. Otaku: os filhos do virtual. São Paulo: Senac, 2000.

CAMPOS, R. Juventude e visualidade no mundo contemporâneo: uma reflexão em torno da imagem nas culturas juvenis. Sociologia, problemas e práticas, n. 63, p. 113 $137,2010$.

DAWSEY, J. Sismologia da performance: ritual, drama e play na teoria antropológica. Revista de Antropologia, v. 50, n. 2, p. 527-570, 2007.

FERNANDES, C. S. Co(rpo)municabilidade e sociabilidade: a imagem e a estética como vetores de comunicação-comunhão. In: ENCONTRO DE ESTUDOS MULTIDISCIPLINARES EM CULTURA (ENECULT), 4., 2008, Salvador. Anais... Salvador: UFBA, 2008.

FERNANDES, C. S. Sociabilidade, comunicação e política: a rede MIAC como provocadora de potencialidades estético-comunicativas na cidade de Salvador. Rio de Janeiro: E-papers, 2009.

FOUCAULT, M. O corpo utópico, as heterotopias. São Paulo: N-1 Edições, 2013.

Outros espaços. Rio de Janeiro: Forense Universitária, 1984.

GIDDENS, A. Modernidade e identidade. Rio de Janeiro: Zahar, 2002.

GOFFMAN, E. A representação do eu na vida cotidiana. Petrópolis: Vozes, 1983.

JUNG, S. K-pop, Indonesian Fandom, and Social Media. Transformative Works and Cultures, n. 8, 2011. Disponível em: http://journal.transformativeworks.org/index.php/ twc/article/view/289/219. Acesso em: 20 out. 2017.

KARAM, K.; MEDEIROS, M. C. Subcultura, estratégia e produção de gosto: uma análise do k-pop no Brasil. In: CONGRESSO INTERNACIONAL DE COMUNICAÇÃO E CONSUMO (COMUNICON), 2015, São Paulo. Anais... São Paulo: ESPM, 2015. LOURENÇO, A. L. C. Otakus: construção e representação de si entre aficionados por cultura pop nipônica. 2009. 365f. Tese (doutorado em Antropologia Social) - Museu Nacional, Universidade Federal do Rio de Janeiro, Rio de Janeiro, 2009.

MACHADO, C. A. Processos socioeducativos dos animencontros: a relação de grupos juvenis com elementos da cultura midiática japonesa. 2009. 192f. Tese (doutorado em Educação) - Pontifícia Universidade Católica do Rio de Janeiro, Rio de Janeiro, 2009. MAFFESOLI, M. Homo Eroticus: comunhões emocionais. Rio de Janeiro: Forense, 2014.

O tempo das tribos: o declínio do individualismo nas sociedades de massa. Rio de Janeiro: Forense Universitária, 1987.

MAUSS, M. Sociologia e antropologia. v. II. São Paulo: Edusp, 1974.

NUNES, M. R. F. Cena cosplay: breves narrativas de consumo e memória pelas capitais do Sudeste brasileiro. In: Cena cosplay: comunicação, consumo, memória nas culturas juvenis. Porto Alegre: Sulina, 2015. p. 23-76. 
OLIVEIRA, A. C. M. A.; FERNANDES, C. S.; SOUZA, J. S. Corpo, comunicação e cidade: a estética como élan comunicacional. In: COLÓQUIO MULTITEMÁTICO EM COMUNICAÇÃO (MULTICOM), 3., 2008, Natal. Anais... Natal, 2008.

SASAKI, E. Qual a relação entre a imigração e a cultura pop japonesa no Brasil? In: CONGRESSO INTERNACIONAL "ASIA Y AFRICA. Conexiones, intercambio y nuevos abordajes acadêmicos desde América Latina”, XIV, 2013, La Plata. Anais... La Plata: Aladaa, 2013.

SATO, C. Japop: o poder da cultura pop japonesa. São Paulo: NSP Hakkosha, 2007.

SCHECHNER, R. Pontos de contato entre o pensamento antropológico e o teatral. Cadernos de Campo, n. 20, p. 213-236, 2011.

. Performance studies: an introduction. Oxon: Routledge, 3. ed., 2006.

SILVA, C. G. Cultura juvenil em dance games como forma de lazer em espaços públicos de Brasília. 2013. 67f. Trabalho de conclusão de curso (graduação) - Faculdade de Educação Física, Universidade Federal de Goiás, Formosa, 2013.

SOARES, G. T. Cosplay: imagem, corpo, jogo. 2013. 86f. Dissertação (mestrado em Comunicação e Semiótica) - Pontifícia Universidade Católica de São Paulo, São Paulo, 2013.

SOARES, T. Percursos para estudos sobre música pop. In: FERRAZ, R.; CARREIRO, R.; SÁ, S. (Orgs.). Cultura pop. Salvador: UFBA; Brasília: Compós, 2015.

ZUMTHOR, P. Performance, recepção, leitura. São Paulo: Cosac Naify, 2007.

\section{Sobre as autoras}

Cíntia Sanmartin Fernandes - Pós-doutora pela Escola de Comunicação da UFRJ e pelo Programa de Comunicação e Semiótica da PUC-SP (2007-2010). Doutora e mestre em Sociologia Política pela Universidade Federal de Santa Catarina, graduada em Ciências Sociais pela Universidade Estadual de Campinas. Professora adjunta da Faculdade de Comunicação Social da Universidade do Estado do Rio de Janeiro (FCS-Uerj) e do Programa de Pós-graduação em Comunicação (PPGCOM/Uerj).

Paula Rozenberg Travancas - Doutoranda e mestre pelo Programa de Pós-graduação em Comunicação da Universidade do Estado do Rio de Janeiro.

Data de submissão: 27/10/2017

Data de aceite: 20/03/2018 